\title{
Reviewing the evidence and identifying gaps in family planning research: The unfinished agenda to meet FP2020 goals
}

\author{
Ian Askew \\ Population Council \\ Martha Brady \\ Population Council
}

Follow this and additional works at: https://knowledgecommons.popcouncil.org/departments_sbsr-rh

Part of the Community-Based Research Commons, Demography, Population, and Ecology Commons, Family, Life Course, and Society Commons, International Public Health Commons, Quantitative, Qualitative, Comparative, and Historical Methodologies Commons, and the Women's Health Commons How does access to this work benefit you? Let us know!

\section{Recommended Citation}

Askew, lan and Martha Brady. 2013. "Reviewing the evidence and identifying gaps in family planning research: The unfinished agenda to meet FP2020 goals," background document for the Family Planning Research Donor Meeting, Washington, DC, December 2012. New York: Population Council. 


\section{REVIEWING THE EVIDENCE AND IDENTIFYING GAPS IN FAMILY PLANNING RESEARCH}

THE UNFINISHED AGENDA TO MEET FP2020 GOALS

IAN ASKEW AND MARTHA BRADY

BACKGROUND DOCUMENT PREPARED FOR

FAMILY PLANNING RESEARCH DONOR MEETING

3-4 DECEMBER 2012 
This document was made possible by the generous support of the American people through the United States Agency for International Development (USAID) under the terms of Cooperative Agreement No. GPO-A-00-04-00019-00. The contents are the responsibility of the authors and do not necessarily reflect the views of USAID or the United States Government.

\section{(2) Population Council}

The Population Council confronts critical health and development issues-from stopping the spread of HIV to improving reproductive health and ensuring that young people lead full and productive lives.

Through biomedical, social science, and public health research in 50 countries, we work with our partners to deliver solutions that lead to more effective policies, programs, and technologies that improve lives around the world. Established in 1952 and headquartered in New York, the Council is a nongovernmental, nonprofit organization governed by an international board of trustees.

www.popcouncil.org

Askew, Ian, and Martha Brady. 2013. "Reviewing the evidence and identifying gaps in family planning research: The unfinished agenda to meet FP2020 goals," background document for the Family Planning Research Donor Meeting, Washington, DC, 3-4 December 2012. New York: Population Council.

(C) 2013 The Population Council, Inc. 


\section{ACKNOWLEDGMENTS}

This paper was prepared as a background document for the Family Planning Research Donor Meeting, organized by USAID, DFID, Bill \& Melinda Gates Foundation, and AusAID as part of their collaboration under the Alliance for Reproductive, Maternal and Newborn Health, and in conjunction with WHO. The meeting was held in Washington, DC, on December 3-4, 2012. The authors would like to acknowledge the contributions of many. From the Population Council, we wish to thank Lauren Katzen and Nancy Termini for their stellar research assistance and painstaking efforts at extracting evidence; Gary Bologh for his excellent editing; Virginia Kallianes for her calm and steady assistance with preparing the glossary and references and with formatting; and Christina Tse and Mike Vosika for help with design and layout. We would like to thank the planning committee responsible for organizing the meeting for their valuable insights: Scott Radloff (USAID), Malcolm McNeill and Sue Kinn (UK Department for International Development), Clea Finkle (Bill \& Melinda Gates Foundation), Moazzam Ali and Mario Festin (WHO) and Stanley Luchters (Burnet Institute/AusAID Women and Children's Health Knowledge Hub). We also appreciate the unwavering support of the meeting organizers: Linda Sussman (USAID,) Jill Keesbury and Molly Canty (RMNH Alliance), and Margaret Neuse (Facilitator). 


\section{Contents}

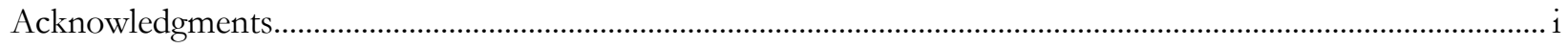

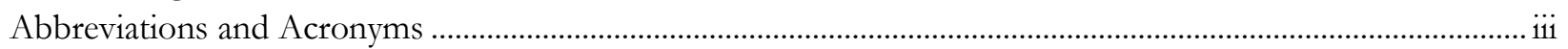

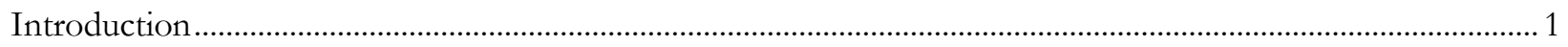

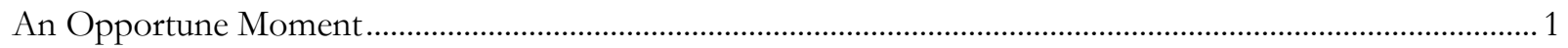

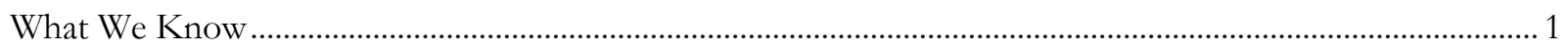

Methodology

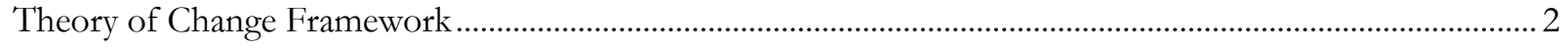

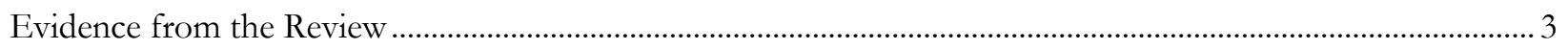

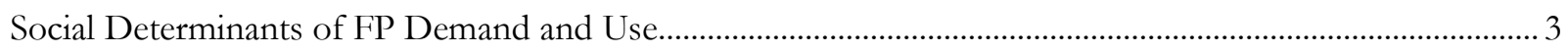

Awareness of FP and Contraceptive Technologies .................................................................................. 5

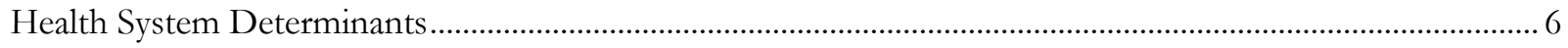

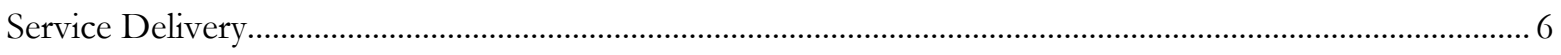

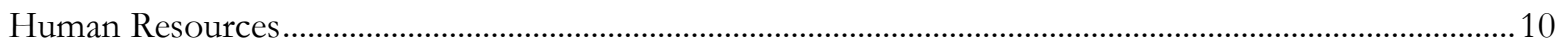

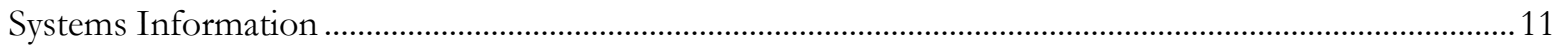

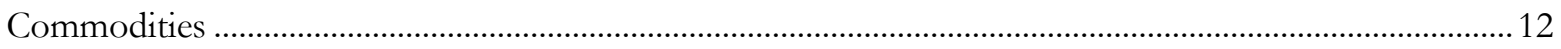

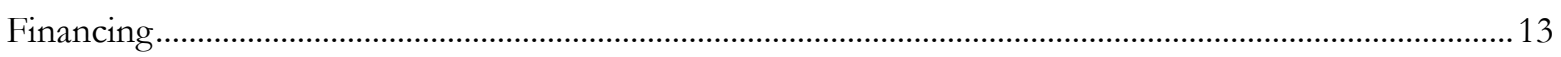

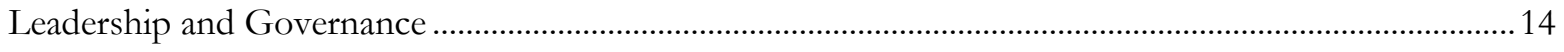

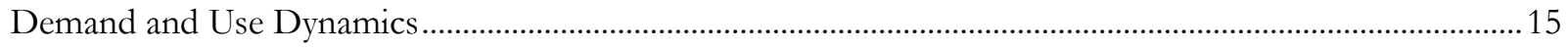

Associations between FP Use, Non-Use, and Distal Outcomes...................................................................16

Using Research, Monitoring, and Evaluation for Guidance Development...................................................17

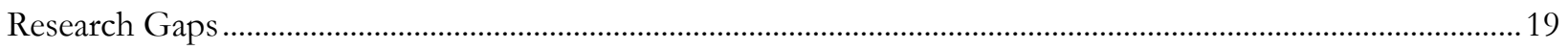

Approaches to Determining Inequities and Identifying Needs of Underserved and Vulnerable

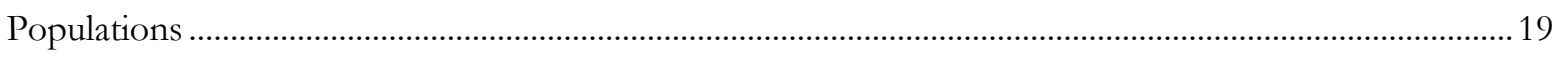

Methodologies to Prospectively Evaluate Structural Interventions to Reduce Inequities and Vulnerability

Interventions to Meet the Needs of Unmarried and Married Adolescents.................................................20

Interventions to Improve and Sustain the Quality of FP Services .................................................................20

Strategies for Scaling up Effective Models of Integrated Services ............................................................ 20

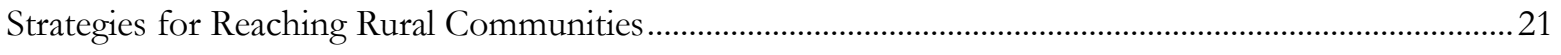

Strategies for Reaching Urban Poor Populations .......................................................................................2 21

Techniques for Defining and Shaping Contraceptive Markets to Improve Availability and Access.........21

Innovative Financing Mechanisms to Expand Access and Increase Affordability .....................................22

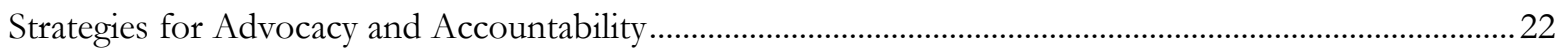

Understanding the Dynamics of Contraceptive Decision-Making and Use ..............................................22

Building Capacity and Improving Methods to Generate and Use Evidence on FP..................................23

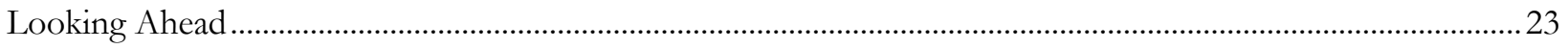

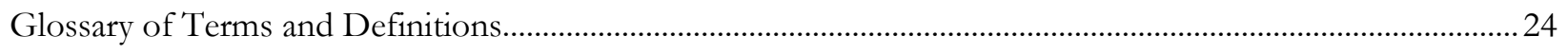

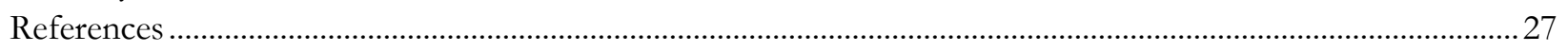




\section{Abbreviations and Acronyms}

\begin{tabular}{|c|c|}
\hline $\mathrm{ANC}$ & Antenatal care \\
\hline ART & Antiretroviral therapy \\
\hline CBD & Community-based distribution \\
\hline ССТ & Conditional cash transfer \\
\hline CHW & Community health worker \\
\hline CVR & Contraceptive vaginal ring \\
\hline DHS & Demographic and Health Survey \\
\hline $\mathrm{EC}$ & Emergency contraception \\
\hline ehealth & $\begin{array}{l}\text { Electronic communication technology, such as computers and mobile phones, } \\
\text { used for health services and information }\end{array}$ \\
\hline FC & Female condom \\
\hline FP & Family planning \\
\hline HIV & Human immunodeficiency virus \\
\hline HMIS & Health management information system \\
\hline IUD & Intrauterine device \\
\hline LAM & Lactational amenorrhea method \\
\hline $\mathrm{M} \& \mathrm{E}$ & Monitoring and evaluation \\
\hline mhealth & Mobile communication technology used in health care delivery systems \\
\hline PAC & Postabortion care \\
\hline PBF & Performance-based financing \\
\hline PLWHA & People living with HIV/AIDS \\
\hline RCT & Randomized controlled trial \\
\hline RH & Reproductive health \\
\hline SBCC & Social and behavior change communication \\
\hline SDM & Standard Days Method \\
\hline TBA & Traditional Birth Attendant \\
\hline TM & Total market \\
\hline UNDP & United Nations Development Programme \\
\hline UNFPA & United Nations Population Fund \\
\hline WHO & World Health Organization \\
\hline
\end{tabular}




\section{INTRODUCTION}

"The evidence is clear: Family planning improves health, reduces poverty, and empowers women" (Bongaarts et al. 2012). Voluntary high-quality family planning programs speed fertility declines, thus improving health and boosting economies. Indeed, they are among the most cost-effective health and development investments available to governments (Bongaarts et al. 2012; Cleland et al. 2006). The case for family planning has been made, yet more than 200 million women in the developing world who want to avoid pregnancy are not using a modern contraceptive method. The reasons for this are many, including lack of access to information and appropriate health services, traditional gender norms that impede women's ability to adopt contraception, community and gatekeepers' (husband, in-laws, partners) opposition, real and perceived concerns about safety and side effects, and cost, among others. Underlying socio-behavioral issues, including risk perception, ambivalence, and social costs, may also play a role in demand and use.

\section{An Opportune Moment}

After a decade of waning investment in family planning (FP), we are now witnessing a resurgence of interest and funding. This is an opportune moment to address the unfinished family planning agenda (Cleland et al. 2006). The International Family Planning Summit held in London in July 2012 witnessed unprecedented levels of financial and political commitment from national governments and the international community to achieve the goal of 120 million new users of contraceptives by 2020 . This goal is to be achieved through a coordinated effort, known as FP2020, through implementing four broad objectives:

- Increase political commitment and accountability for delivery of family planning services

- Contribute to substantially increased access to family planning information, services, and supplies

- Create a healthy and sustainable market for family planning commodities

- Adapt and develop new and innovative contraceptive methods

This paper is intended to help guide discussions and considerations regarding the key evidence gaps and research investments needed to achieve the FP2020 goal and objectives. The paper focuses primarily on the social science, implementation, and operations research that will be needed to achieve the first three objectives. The contraceptive research and development (R\&D) needed for the fourth objective is the subject of another initiative.

\section{What We Know}

Simply stated, we know that the most effective approach to achieving the FP2020 goal is to ensure universal access to family planning, so that all women have access to a full range of effective, acceptable, and affordable contraceptive methods appropriate to their needs and situation, made available through multiple service delivery channels in a reliable fashion. Achieving this, however, requires political will, human and economic resources, technical expertise, vision, and leadership. Context also matters. The diversity of needs, populations, and reproductive intentions of individuals and couples, along with the maturity of programming and the strength of particular national health systems, will influence the effectiveness and impact of investments in FP2020. 
Research on family planning has made great strides in generating evidence about how it improves lives through reducing adverse health outcomes associated with unintended pregnancy, reducing poverty by facilitating economic development and improving women's and girls' social status. As the availability and use of FP information and services have increased over the past three decades, however, so has the need for evidence-based policy guidance, as well as evidence-based strategies for programming and financing. Moreover, the degree to which strategies and best practices proven through small-scale projects can be and have been scaled up within national health systems is not well understood.

The design and implementation of FP services over this period has benefited from donor investments in social science, implementation, and operations research that has generated a substantial body of evidence, some of which is context-specific but much of which can be generalized across social milieu and health systems (Jacobstein et al. 2013). This paper reviews the evidence base to identify what is currently known about FP services and what evidence gaps still exist for which further investments in research will be critical for informing the design, implementation and evaluation of FP2020 initiatives.

\section{METHODOLOGY}

Given the scale and diversity of the evidence base, we initially identified a number of rigorous literature reviews that have been conducted on the topic and published within the past five years. Where appropriate, other key documents with relevant evidence were gleaned from reviews and informed experts (Jacobstein et al. 2013). In addition, the recent World Health Organization (WHO) prioritization exercises (Ali et al. 2012; Hindin et al. 2013)and USAID's 'High Impact Practices' (HIP) documents (K4Health 2012) were reviewed. Several systematic reviews, some following the Cochrane review methodology, were also identified. From these reviews, and drawing from expert informants and our own experience, we identified documentary sources that were considered to present research-based evidence of sufficient quality and rigor to be included. We included reviews that reported evidence generated through a range of research methods (demographic, social science, epidemiologic, policy analysis, and implementation science/operations research) and excluded evidence from biomedical, clinical trials, and other product development research. The evidence was collected and collated according to a theory of change framework.

\section{Theory of Change Framework}

Numerous frameworks exist for conceptualizing the determinants and consequences of contraceptive use dynamics. We approached this review and analysis through the lens of a theory of change comprising five critical and interrelated elements:

- Social determinants of FP demand and use

- Health system determinants

- Demand and use dynamics

- Associations between FP use, non-use, and distal outcomes

- Research, monitoring, and evaluation

Based on this theory of change, and in consultation with the expert informants, we prepared a detailed list of topics and assigned them to the appropriate elements in a Review Framework that guides the presentation of the summary of evidence below. 


\section{THEORY OF CHANGE: REDUCING UNINTENDED PREGNANCY}

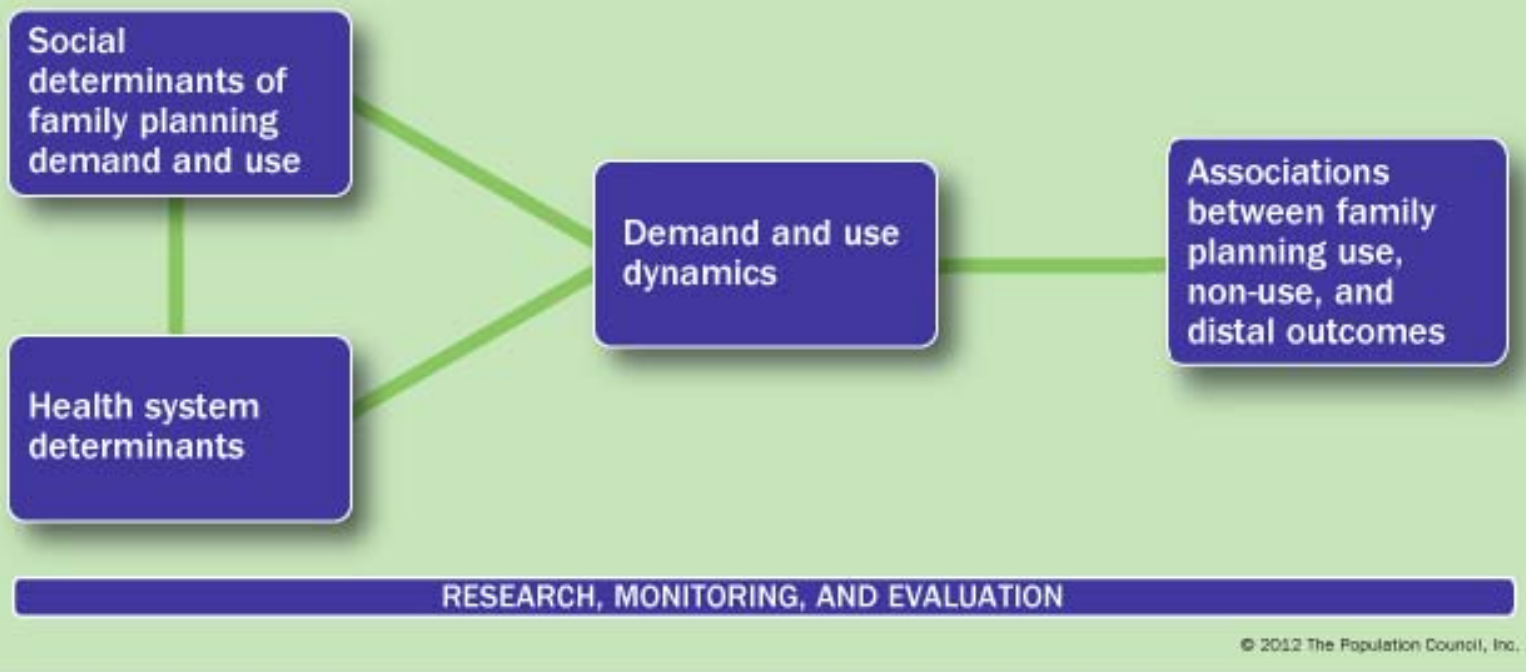

\section{Evidence from the Review}

\section{Social Determinants of FP Demand and Use}

Many social determinants can influence demand for and use of FP, either individually or in various combinations. In developing countries, the most influential determinants are typically: girls' and women's social status and decision-making power; level of education; marital status; economic status; age; place of residence; and experience of violence (Bongaarts et al. 2012; Cleland et al. 2006; Creanga et al. 2011; Gillespie et al. 2007; Malarcher et al. 2011; DFID 2010b; DFID 2010a; Ortayli and Malarcher 2010). In some settings, ethnicity, migrant status, and HIV status can also be key determining factors. The role of these social determinants in shaping demand for and use of FP is well documented (Cleland et al. 2006; DFID 2010b), and evidence from multiple settings and populations exists that can be used to advocate for the importance of understanding which factors are the most influential in determining demand and use in a particular setting, and, in turn, for identifying those populations that are the most underserved and have the highest unmet need.

Framing this evidence from an equity perspective is critically important so as to focus policy and programmatic attention on identifying the most disadvantaged, vulnerable, and underserved populations with unmet need (Creanga et al. 2011; Gillespie et al. 2007). Reducing inequities in access and use are central to implementing a rights-based approach to providing FP services and inherent in the goal of MDG 5B: achieving universal access to reproductive health $(\mathrm{RH})$, including family planning. Inequity reduction is also central to FP2020's focus on rights and empowerment.

The extent to which social determinants interact and influence demand for, access to, and use of FP services, and consequently contribute to inequities, is highly context-and population-dependent. Situationspecific analyses should thus be undertaken to generate evidence for guiding rights-based policy/program development in all countries (Ortayli and Malarcher 2010). For example, most, but not all, Demographic and Health Surveys (DHS) include standard indicators for many of the social determinants and thus 
provide an easily accessible data source (Malarcher et al. 2011; Ortayli and Malarcher 2010). Most of the evidence on social determinants comes, however, from cross-sectional surveys, such as the DHS, whereas longitudinal data could better demonstrate causality. Numerous demographic surveillance systems (DSS), which collect longitudinal data on a range of health indicators, exist in developing countries, but unfortunately very few routinely collect data on contraceptive use and fertility.

Although the DHS can provide much useful data for an overall understanding of many social determinants of unmet need and unintended pregnancy, it generally lacks sufficient data to enable a full understanding of unmet need among key populations suffering from social inequities, notably married and unmarred adolescents, marginalized ethnic populations, urban slum dwellers, and people living with HIV/AIDS (PLWHA). Because the adverse health, social, and economic outcomes of unintended pregnancies among these populations are generally more serious than among other populations (Gipson, Koenig and Hindin 2008; Malarcher et al. 2011), in-depth analyses of vulnerable populations are essential to generate evidence for rights-based policy and program development.

Although the evidence of population-level associations is fairly strong and convincing (DFID 2010b), evaluated interventions that explicitly seek to address the underlying determinants that lead to inequities in access to and use of FP are relatively scarce (DFID 2010b; DFID 2010a). This is primarily because such "structural" interventions are usually implemented with the goal of broader social change and require large-scale complex interventions that may or may not explicitly include changes in reproductive intentions and contraceptive use. However, structural interventions are emerging that are intended to have a direct impact on access to and use of FP among populations suffering from specific inequities. Examples include reaching unmarried adolescents with appropriate information and services, reducing early marriage and reaching married adolescents with supportive information and services, reducing poverty-induced barriers, and reaching PLWHA. Evidence gaps persist in how to tackle these determinants, as well as for interventions that address: i) violence reduction and contraceptive use, especially for adolescent girls; ii) unintended pregnancy among populations living in urban slums, especially adolescents; and iii) girls and women engaged in sex work.

Adolescents are a diverse group of 10-19 year olds whose capacities and needs differ by age, sex, living arrangements, area of residence, level of education, and by their marital, childbearing, and employment status. Given this heterogeneity, addressing adolescent RH needs presents complex challenges.

Although some trends in adolescent health and social outcomes have improved over the past three decades - including school enrollment and retention, early marriage, and early pregnancy (WHO 2011)_disparities in many adolescent health outcomes persist by age, income, gender, region, and other socio-cultural factors.

Interventions seeking to reduce sexual risk-taking among adolescents have become increasingly common in developing countries in the past decade. These interventions have taken a variety of configurations, from conventional sex education in schools to multi-component, cross-sector efforts aimed at improving educational and economic opportunities and delaying marriage. Relatively few of these have been rigorously evaluated; and the majority of programs that have been evaluated are small in scale and implemented over a relatively brief period. There is a paucity of information concerning intervention costs, and little evidence regarding long-term behavioral effects (Speizer, Magnani and Colvin 2003). 
Key determinants of adolescent pregnancy include early marriage, sexual coercion, and lack of access to and use of appropriate contraceptives. A recent systematic review (Lee-Rife et al. 2012) found little evidence concerning the effect of various non-health interventions on unintended pregnancy, and the evidence that does exist is generally weak. As a result, WHO made several research recommendations: i) assess the impact of improved educational availability on age of marriage; ii) assess the feasibility and long-term impact of economic incentives to girls and their families as a means of delaying age of marriage; iii) determine the effect of formal and non-formal education on adolescent pregnancy prevention; and iv) determine the effect of school-retention interventions (e.g., conditional or unconditional cash-transfer interventions) on delaying pregnancy. For addressing coerced sex, WHO recommends engaging men and boys to alter gender norms and normative behaviors, and highlights the need for research to assess how laws and policies to prevent coerced sex have been formulated, enforced, and monitored and to determine the effectiveness of these laws and policies in preventing coerced sex among adolescents.

\section{Awareness of FP and Contraceptive Technologies}

Raising awareness of the benefits of preventing unintended pregnancies and thereby enabling individuals and couples to plan "children by choice not chance" through using contraceptive technologies has a long history (Bongaarts et al. 2012; DFID 2010a). A substantial evidence base exists regarding the use of information, education, and communication (IEC) and social and behavior change communications (SBCC) strategies to generate demand for FP generally, and (to a lesser extent) for specific groups of contraceptive technologies (e.g., long-acting reversible methods, male methods, etc.).

Four broad categories of demand generation interventions can be considered. Evidence from quasiexperimental designs indicates that mass media campaigns can generate an immediate demand for FP services and are associated with approval of FP and greater partner communication about FP and increased contraceptive use. "Edutainment" programs through radio and TV dramas are associated with increased contact with FP providers, greater use of FP, and decreased desired family size (Bongaarts et al. 2012; Mwaikambo et al. 2011; Westoff, Koffman and Moreau 2011). Community mobilization approaches are usually implemented jointly with service delivery through community health worker (CHW) programs or social marketing programs, both of which have been found to have substantial effects on the demand for and use of FP (DFID 2010a). Evidence also supports the effectiveness of interventions that increase interpersonal communications, especially between young people, partners/couples, other family members, or social peers (DFID 2010a; Mwaikambo et al. 2011). Recent developments in mhealth for generating FP demand have stimulated much interest, and several pilot projects are currently underway, but little evidence exists because results have not yet been published (L'Engle 2012).

Because vulnerable populations are generally more isolated, poorer and less literate, they are also less likely to be exposed to many of these demand generation interventions (Ortayli and Malarcher 2010). Moreover, the relevance, or perceived relevance, of these messages may be particularly low for vulnerable populations, for example married girls and female sex workers. The extent to which vulnerable populations are reached by these types of interventions and the extent to which the interventions have an effect on such populations remain under-researched and should be highlighted in future evaluations of demand generation interventions. Social marketing organizations are often required to report on the extent to which their campaigns reach the poorest and most vulnerable populations, and such analyses should be integral to the design and evaluation of future demand generation interventions. 
Reducing unmet need is the primary goal of FP2020. Focusing on reducing unmet need implicitly assumes that a demand for FP already exists and is being partially met. However, although awareness of the benefits of FP are widely known in most regions of the world (apart from West Africa), knowledge of contraceptive technologies and how to obtain them is often incomplete and inaccurate. Thus, unfounded concerns regarding side effects are widespread, contributing to personal and partner opposition to contraception (Darroch, Sedgh and Ball 2011). Strategic communication strategies (Bongaarts et al. 2012) are therefore still needed within the FP2020 framework, especially for populations without full awareness of the range of contraceptive alternatives available, how they function, and how to access them. The evidence base regarding interventions tailored to address method-related concerns is thin, however.

\section{Health System Determinants}

National health systems largely (but not solely) determine the institutional structures and processes through which FP is delivered and accessed. When considering a national health system, it is important to consider these systems from the perspective of the "total market" (TM) through which FP is made available, which includes public, commercial, not-for-profit, and faith-based sectors (Barnes et al. 2012). To organize the evidence available concerning FP delivery through a total market health system, we adopt the framework of WHO's six "building blocks" of health systems: service delivery, human resources, systems information, medicines, financing, and leadership and governance.

\section{Service Delivery}

Globally, the number and type of service delivery channels through which FP is delivered has increased dramatically over the past two decades, reflecting both expansion within the public sector and the growth of other sectors as sources of FP. To simplify the presentation of evidence, we cluster these into seven broad channels: clinic-based; integrated with other services; community-based; mobile outreach; social marketing and pharmacies; adolescent-friendly services; and other vulnerable populations.

Clinic-based. Clinic-based delivery of FP services is still the main delivery channel for married women; increasingly, this may be through non-public sector facilities as the private sector grows in many countries. How to provide clinic-based FP services is broadly understood. The evidence challenges primarily concern improving quality and choice. The key components of high-quality services are wellestablished, as described in the Bruce-Jain framework (Bruce 1990; Jain 2001), and substantial evidence exists that strengthening these components does impact client-provider interactions, client satisfaction, and effective and sustained method use (RamaRao and Mohanam 2003). Numerous quality improvement interventions have been developed, but relatively few have been rigorously evaluated (Mwaikambo et al. 2011; RamaRao and Mohanam 2003). A recent synthesis of the evidence (Jain 2012) yielded two broad conclusions: (a) increasing the number of methods made available to clients increases choice, which leads to more new users, reduced discontinuation through switching, and increased prevalence overall; and (b) improving providers' skills and attitudes enhances their technical competence and ability to identify and meet clients' individual needs. The evidence base for which interventions can most efficiently increase the number of methods offered, and which can most effectively improve providers' skills, particularly in counseling new clients to determine and meet their individual needs, including continued use of hormonal methods, remains limited, however (Cleland et al. 2006; Halpern et al. 2011; RamaRao and Mohanam 2003). 
Evidence is also limited regarding the feasibility and effectiveness of quality assurance and monitoring mechanisms. Several have been piloted over the past two decades, but with little systematic documentation or evaluation. Key issues concerning standardized indicators, data-collection systems, and feedback and data utilization mechanisms remain under-researched. Quality monitoring and assurance feature prominently in FP2020, particularly within the Monitoring and Accountability Working Group. It is hoped that this will encourage investment in generating evidence regarding how such mechanisms can be standardized and can function effectively and efficiently.

Increasing engagement of the commercial sector in providing FP through private clinics is particularly noticeable through the burgeoning of social franchising. Recent reviews (Madhavan and Bishai 2010; Mwaikambo et al. 2011; Stephenson et al. 2004) find strong evidence that franchising does increase access to and use of FP services, moderate evidence of improved quality, and moderate evidence of increased use by the poor. The extent to which franchising addresses equity is, however, uncertain. Only one study has addressed cost-effectiveness, but it was inconclusive. Given the potential of this approach, further research is justified regarding its effect on quality of care and equity as well as its relative costeffectiveness.

Integrating FP with other services. Increasing emphasis is being placed on integrating FP into other health services, acknowledging both that women's RH needs are often multiple and that a visit to a clinic represents a valuable and perhaps rare opportunity to address a woman's FP needs. The evidence base concerning the feasibility, acceptability, effectiveness, and cost-effectiveness of integrating FP into various maternal, infant, and child health services is extensive, yet awareness of this evidence and its routine use in programming, especially for postpartum FP services, remains remarkably limited. Recent reviews usefully summarize the evidence (Hiller, Griffith and Jenner 2007; MCHIP 2012; Vernon 2009) and provide programmatic recommendations for which models of integration with maternal, newborn, and child health services have been demonstrated to be effective and thus should be scaled-up. There appear to be few major evidence gaps. Some issues that would benefit from further evidence are: how best to link FP counseling during antenatal care (ANC) with postpartum use; how to involve male partners; whether tubal ligations can be offered safely and with informed choice following caesarean sections; whether child immunization visits are a cost-effective opportunity; and method preferences among postpartum women living with HIV (MCHIP 2012). Women at 12 months postpartum have extremely high levels of unmet need (near 65\%); thus, investing in scaling up evidence-based postpartum FP strategies should be a priority for FP2020.

For almost two decades, postabortion care (PAC) has explicitly incorporated counseling and, if desired, delivery of FP. When FP is routinely offered to PAC clients, the evidence is unequivocal that clients are more likely to receive a contraceptive method than when it is not (USAID 2012c) and so is considered a proven best practice. The one study to evaluate longer-term outcomes found that exposure to postabortion FP resulted in significantly fewer abortions and unintended pregnancies during the 12month follow-up period (Johnson et al. 2002; USAID 2012c). No study exists, however, on the impact on maternal mortality and morbidity of providing postabortion FP (Tripney et al. 2011; Tripney, Kwan and Bird In press).

In most developing countries, post-rape care is still a nascent $\mathrm{RH}$ service, although growing recognition of the scale and severity of sexual assault means greater investment in piloting countryspecific models and preparing for scale-up. Emergency contraception (EC) is an integral component of any post-rape care model, as $5-18 \%$ of rapes result in a pregnancy. Evidence currently available is 
limited to documenting the feasibility of offering EC within a comprehensive package of services (Keesbury and Thompson 2010). No evidence exists of its effectiveness in reducing pregnancy following rape.

The rationale for integrating FP with HIV services is well-established, both through offering FP within HIV services and HIV services within FP services (Wilcher, Cates and Gregson 2009). Moreover, evidence concerning the feasibility of various models of integration is sufficiently strong to support investment in piloting and scaling up (Church and Mayhew 2009; Spaulding, Brickley and Kennedy 2009). The evidence base describing which models work more effectively, efficiently, and equitably is still modest, and is characterized by generally low levels of scientific rigor. However, recent significant investments in rigorous evaluations of integrated models that measure their association with unintended pregnancies, HIV/STI incidence and stigma, as well as comparisons of outcomes between linked services with stand-alone services, will yield substantial improvements in the quantity and quality of the evidence base over the next couple of years.

Moreover, from an HIV-prevention perspective, evidence from modeling demonstrates that reducing unmet need for FP, and consequently unintended pregnancies, in a population with high HIV prevalence (with or without women knowing their status) has a significant impact on reducing perinatal HIV transmission (Reynolds et al. 2008). A recent review of the evidence by a WHO expert group found conflicting evidence regarding whether women using progestin-only injectable contraceptives may be at increased risk of HIV acquisition. The review recommended that women using progestinonly injectable contraceptives be strongly advised to also use condoms and other preventive measures (WHO 2012a).

Community-based. Community-based distribution (CBD) of FP has been an important strategy in all regions of the world for more than three decades. A vast body of documented experience, together with research-based evidence from numerous evaluations with varying levels of rigor, has demonstrated the acceptability, effectiveness (in generating demand and increasing access and use), and cost-effectiveness of CBD agents, as well as providing programmatic guidance for implementation (Mwaikambo et al. 2011; Phillips, Greene and Jackson 1999).

With the realization that providing FP through multipurpose CHWs is more efficient and better meets women's needs than through CBD agents, attention has shifted to identifying the evidence concerning CHWs as a source of FP information and services. A recent review (USAID 2012a) using evidence with varying levels of rigor showed that: (a) CHWs can meet the immediate and growing need for human resources where services are most needed; (b) CHWs can help reduce inequities in FP use and particularly for women with constrained mobility; and (c) CHWs can safely and effectively provide a wide range of methods, including pills, condoms, injectables, Standard Days Method (SDM), lactational amenorrhea method (LAM), and EC. Preliminary evidence also indicates that under appropriate conditions, CHWs can provide implants and intrauterine devices (IUDs). Further evidence is needed concerning the safety and impact of CHWs providing these long-acting methods. Evidence gaps also remain concerning the role of CHWs in meeting the needs of unmarried adolescents, recently married girls, males, and urban slum populations; the relative cost-effectiveness of CHWs compared with clinicbased and mobile outreach models; and the feasibility and effectiveness of outreach workers in other sectors (e.g., agriculture, development) as FP providers. 
Mobile outreach. Provision of long-acting contraceptive methods by a mobile team of trained providers, in a modified vehicle or in a temporary facility or camp, has been a strategy used for many years but with little research-based evidence to describe performance or effectiveness. A recent review of the existing evidence (USAID 2012b) indicates that, in many settings, mobile outreach can: (a) supply between onefifth and more than one-half of all users of particular methods; (b) outperform fixed facilities and at a lower cost; (c) reduce some inequities by reaching some underserved populations, especially those living in remote locations; and (d) reach women who have never previously used any FP. The evidence base remains limited, however, regarding issues such as women's health-seeking behaviors for complications, switching or discontinuation, client satisfaction, overall quality of service, reaching vulnerable populations living in remote locations, and the cost-effectiveness of mobile outreach.

Social marketing and pharmacies. Using commercial-marketing techniques to promote socially beneficial behaviors and make available subsidized FP commodities and services through commercial outlets is an increasingly popular service delivery model, particularly for delivering short-acting methods such as pills (including EC), condoms, SDM (cycle beads) and injectables. A recent review (Madhavan and Bishai 2010) found moderate evidence that social marketing increases access to FP products and messages, though their effect on inequities was not measured. Strong evidence was found of the cost effectiveness of social marketing, and moderate evidence that increasing price reduces use. One review (Chapman and Astatke 2003) found that the socioeconomic status of women served through social marketing tends to be lower than women purchasing commercial brands and higher than those who obtain their products from the public sector.

Although pharmacies often participate in social marketing programs, little evidence exists regarding the role that pharmacies and drug shops can play when specific interventions are introduced to strengthen their capacity to offer FP services. A recent review (Solo and Malarcher 2012) summarizes the limited evidence of their ability to safely provide many methods, and their potential to reach urban poor populations, including unmarried adolescents and males who may be stigmatized when visiting clinics. It also notes that rigorous evidence is lacking on these issues as well as on quality of care and the costeffectiveness of the approach.

Married and unmarried adolescents. Many interventions have been developed to reduce health systems barriers for adolescents, but few have been rigorously evaluated. A recent systematic review (WHO 2011, 2012c) found little evidence, and the evidence that does exist is generally fairly weak. As a result, several research recommendations were made: (a) identify feasible and effective interventions that result in the formulation of laws and policies that reduce barriers to adolescents accessing contraceptives; (b) identify and evaluate interventions that influence community members' support for access to contraceptives among adolescents; (c) identify feasible and effective interventions to improve the availability of overthe-counter hormonal contraceptives to adolescents; (d) determine the effectiveness of interventions that provide accurate information and education about contraceptives in various settings and populations (both in-school and out-of-school); (e) identify feasible and effective interventions that involve adolescent and adult males in decisions concerning contraceptive use by partners and by themselves, including interventions that aim to transform gender norms; ( $f$ ) determine the feasibility, sustainability, and impact of reducing the cost of contraceptives for adolescents.

The majority of sexually active adolescent girls in developing countries are married (Haberland 2003), yet health system-based interventions to address the FP needs of married adolescents are relatively new, and generally seek to reach and support married adolescent girls and their husbands and families with 
targeted activities and services. Few rigorous evaluations have been undertaken but a number of promising practices are emerging from studies using quasi-experimental designs. Such studies feature combined community, couple, and individual SBCC strategies to build a supportive social environment, and education-and home-based supply of FP, especially during the postpartum period following the first birth (DFID 2010a).

Other vulnerable populations. The evidence base regarding the particularities of delivering FP services to urban slum dwellers, and especially to young people, is growing with recent substantial investments in urban-focused FP programs and an independent, complementary evaluation project. More evidence will be needed as the number and range of urban-focused interventions expands rapidly through FP2020; in particular, evidence of such interventions to reduce inequities within urban populations, especially young and unmarried populations. The private sector is likely to feature prominently as a source of commodities, and the electronic media, especially mobile phones, as a source of information. As urban slum populations continue to grow exponentially and with young populations, the importance of generating a rigorous evidence base to guide programming for meeting the needs of the urban youth living in poverty cannot be exaggerated.

As noted above, the evidence base for interventions that meet the FP needs of women living with HIV is growing rapidly through both research and experience. With an initial focus on integrating FP services into prevention of mother-to-child transmission (PMTCT) and ART services for HIV-positive women in high prevalence settings, there are increasing efforts to determine the client's HIV status during FP, ANC, and postpartum services so that the consultation can be tailored to meet their needs during a routine consultation rather than through stand-alone HIV services. Evidence for how this expanded service can best be done is still emerging.

Unintended pregnancy and use of contraceptives among sex workers is poorly understood. No systematic review of this sparse literature has been conducted. Such a review would be helpful because the evidence available is unclear regarding whether sex workers have higher or lower levels of unmet need than the general population. Nomadic and migratory populations, although relatively small in number, are highly vulnerable and their needs can be acute. No evidence exists concerning service delivery or models for reaching them, however.

\section{Human Resources}

Many cadres of health workers have been trained to provide FP information, counseling, and services. Task shifting and sharing are currently being promoted as a strategy for expanding access to FP through enabling larger numbers of health workers to offer a wider range of methods. A recent review of the task sharing evidence (WHO 2012b) produced recommendations for which cadre could safely and effectively provide which types of contraceptive method. This review also identified some evidence gaps that need to be addressed through rigorous research so that a determination can be made concerning whether the following cadres can provide the following contraceptives: (a) trained Lay Health Workers and Traditional Birth Attendants (TBAs) providing implants; (b) auxiliary nurses providing IUDs and vasectomy; (c) auxiliary nurse midwives providing vasectomy; and (d) nurses and midwives providing tubal ligation and vasectomy. It also recommends two situations in which cadres should provide methods although with targeted monitoring and evaluation (M\&E): i) Lay Health Workers and TBAs providing injectables; and ii) auxiliary nurses and auxiliary nurse midwives providing implants. Additionally, the review recommended that, for services for which the evidence does support task 
shifting or sharing without further research—namely, auxiliary nurses and auxiliary nurse-midwives providing injectables, and nurses and nurse-midwives providing implants-national programs should be provided with technical assistance to rapidly amend policies and programs to scale up the evidence-based best practices.

As health systems expand their capacity to offer FP services, a focus on task sharing should not divert attention from broader human resource concerns that can prevent health systems from functioning at full potential (DFID 2010b). Staff shortages, their distribution and rotation, skills competency, lack of supervision, and other human resource issues, are frequently cited as barriers during implementation of new FP interventions. Localized evidence is needed to identify solutions to these problems that can be generated primarily through health systems research methods such as training audits, competency assessments, case studies, health facility assessments, and policy analysis.

A second area in which evidence is needed urgently is the role of electronic and mobile information and communication technology for training, monitoring, and supervising health workers. Despite the great interest in and potential for these technologies to improve provider competence and system efficiency, no rigorous evidence of feasibility, acceptability, effectiveness, and cost-effectiveness exists. Great care is needed, therefore, to ensure that large-scale ehealth/mhealth interventions are not rolled out without sufficient evidence to determine how their introduction will impact the health system.

\section{Systems Information}

Effective and efficient delivery of FP services requires the production, analysis, and communication of data regarding the performance of service delivery sites and providers, and the relation between use of FP services and achievement of reproductive intentions through prevention of unintended pregnancy. Performance monitoring will be critical if the FP2020 goals are to be achieved. The collection, processing and use of performance-related data is usually organized through the design and implementation of an M\&E strategy. M\&E strategies are informed primarily through experiential rather than research-based evidence and usually conceptualized according to logical frameworks based on a "theory of change." At the heart of most M\&E strategies for FP service delivery is a health management information system (HMIS) that records and reports the delivery of FP services.

Most national HMISs are notoriously weak at monitoring FP performance. Incorporating data from the non-public sector into an HMIS has proved difficult. Because HMISs also do not usually track client characteristics, monitoring whether inequities are being reduced will be difficult without changes. Because they also do not regularly monitor quality of care, sufficient investments will be needed to strengthen and amend national HMISs and link them with the evolving global framework being developed by the FP2020 Performance Monitoring and Accountability Working Group. Moreover, if an accountability mechanism is to be established and function so that it can routinely track that service delivery is rights-based, it will need to be linked directly with the national HMIS.

Although the overall goal of FP2020, 120 million new users, can be tracked through a strengthened HMIS, the population-level impacts of the various interventions implemented to meet this goal will also need to be measured through data generated through representatively sampled surveys. Historically, the DHS mechanism has provided these data, but with the increased focus on unmet need, unintended pregnancy, and equitable access — all measures that require population-level samples — there is likely to 
be a need for increased investment in surveys, including in the human resources to undertake them, analyze the findings, and support the uptake of this evidence by stakeholders and decision-makers.

Paper-based HMISs are increasingly being replaced by electronic systems, handheld devices for data collection and transmission, and computerized analyses are informing budgeting and planning decisions. Despite their rapid increase, rigorously tested and validated electronic HMISs that can be used with ease by program and clinic managers are still a minority. Substantial investment in computerization of national HMISs and in building human resource capacity to use them effectively should be a priority as FP2020 rolls out at the country level.

\section{$\underline{\text { Commodities }}$}

Maximizing global access to FP commodities in accordance with quality assurance requirements at affordable and sustainable prices, or "market shaping," is one of the objectives of FP2020. Problems with FP commodity production, pricing, forecasting procurement needs, efficient supply logistics, and quality assurance have all been identified as key barriers that restrict access and choice for women wishing to use FP, thereby contributing to unmet need. To plan for and implement a market-shaping strategy that will reduce these barriers to develop a more efficient, effective, and equitable market for FP commodities will require substantially more evidence than is currently available. For example, the FP2020 Market Dynamics Working Group is expected to improve processes and tools for demand forecasting, coordinated procurement, harnessing innovative financing, strengthening supply chains, and testing innovative products. All of these processes and tools will require valid, regular data, some of which can be generated through an HMIS, but most will need to be documented and analyzed through new procedures and mechanisms.

In particular, validated TM approaches will be needed to assess the characteristics of existing and likely future markets, and to define the comparative advantage of commercial, social marketing, nongovernmental organization (NGO), and public sector actors in terms of their competence and value for money in delivering a range of products or services to different market segments, including the poorest. Rigorous methods for defining, measuring, and monitoring method mix, both in terms of demand and supply, will be essential for maximizing choice. Evidence to support the bridging from product development to market introduction is lacking. Conceptual frameworks and critical pathways exist, but with limited validation and demonstration of utility across the spectrum of methods.

Some specific evidence gaps exist for the provision of individual contraceptive commodities:

- Condoms: Male condom use is increasing rapidly among unmarried people, especially in Africa. Evidence is needed regarding how to sustain its use after marriage, especially as a dual protection strategy. Evidence concerning programming for female condoms (FC) is increasing slowly; until recently there has been limited interest in FC as a family planning method per se among potential users and providers. Provider and policy bias has inhibited investment in research and programming, although that has begun to change with the recent development of newer models of female condoms coming on the market.

- Contraceptive vaginal rings (CVR): Extensive research is needed regarding how best to introduce and mainstream both progesterone-only and other CVRs. For the latter, market forecasting for developing countries and evidence are needed to inform strategies for affordable production, procurement, and sales. 
- Emergency Contraception (EC): Although evidence-based guidance concerning the introduction and mainstreaming of EC products does exist (Hossain and et al. 2009), the UN Commission on Life-Saving Commodities for Women and Children has included EC (together with implants and FCs) in its list of over-looked commodities. Earmarked investments will become available to expand the evidence base regarding the supply of this commodity.

- Injectables: This is the most rapidly increasing contraceptive commodity being used in Africa. The implications of this rapid increase in access and use need better understanding, especially in countries with high HIV prevalence for which concerns remain about its possible association with HIV acquisition. Conversely, use of injectables in South Asia is relatively limited, and more evidence is needed to determine whether there is greater potential demand and if so, how this could best be met.

- Implants: Evidence concerning implants is fairly complete, with the main gap being the extent to which provision of this method can be task shifted to lower-level cadres to increase access, especially in rural areas. Evidence concerning their use by adolescents is limited.

- IUD/intrauterine system: The evidence regarding reasons for non-use is generally quite good. The main evidence gap is the extent to which method provision can be task shifted to lower-level cadres to increase access, especially in rural areas.

- LAM: Evidence is still needed regarding how best to facilitate the transition from LAM to an effective contraceptive technology after breastfeeding.

- Oral contraceptive pills: No further evidence seems to be needed at this point in time.

- SDM: Evidence suggests that demand exists for SDM and that this can increase as availability and awareness increase. The method is most popular among women not currently using an effective method, thus providing programs a strategy to reach underserved couples; how best to do this needs informing through locally obtained evidence (Lundgren 2012).

- Tubal ligation: Options for easier procedures are currently being explored and evidence is needed to determine the extent to which lower cadres can task share its provision.

- Vasectomy: Evidence is needed concerning the reasons for non-use and to identify innovative and effective ways to communicate messages, especially in Africa.

- What is next? Emerging contraceptive and multipurpose prevention technologies (MPTs): A diverse set of research endeavors will be needed as new technologies enter into clinical trials and pre-introduction studies.

\section{Financing}

Increased effectiveness and efficiency in health systems functioning is intimately tied to the way in which systems are financed. Most public sector and NGO health programs pay for the inputs needed to produce FP services and not for their performance outputs or outcomes (i.e., whether FP services are actually delivered or whether the population's RH improves). Paying for performance (P4P), result-based financing $(\mathrm{RBF})$, output-based aid $(\mathrm{OBA})$, performance-based financing $(\mathrm{PBF})$ performance-based incentives $(\mathrm{PBI})$, and other similar terms describe interventions that finance a health system through paying for the outcomes delivered. Over the past decade, many models have been and continue to be developed and tested using this principle, and indeed some major donors are also configuring their service delivery tenders so that payment is performance-based.

As described by a recent Cochrane review, the evidence base for PBF is presently too weak to draw general conclusions. PBF is not a uniform intervention; its impact depends on the interaction of several variables, including the design of the intervention (e.g., who receives payments, the magnitude of the 
incentives, the targets and how they are measured), the amount of additional funding, other ancillary components such as technical support, and contextual factors including the organizational context in which it is implemented (Witter et al. 2012). For maternal health, an "evidence summit" convened in mid-2012 provided the focus for collating and synthesizing the evidence concerning the full range of financing mechanisms being piloted. The evidence summarized at that meeting is currently being prepared for distribution and should be available by early 2013.

For FP specifically, several PBF mechanisms are being tried (Eichler et al. 2010): donors incorporating $\mathrm{PBF}$ in the way they structure payment to countries by conditioning aid on evidence of health results; national governments transferring funds to sub-national levels of government based partly on attainment of health or coverage targets; donors paying NGOs for results that include FP; rewarding health facilities for quality counseling and availability and use of modern FP methods; reducing financial barriers to accessing FP by selling to poor women vouchers for FP services at subsidized rates from accredited providers; and conditional cash transfer (CCT) programs providing income support to poor families if they meet health and education conditions that include participating in health education talks about FP and some evidence of increased FP use (Mwaikambo et al. 2011). Given the high level of interest in PBF, further investment in research concerning these various PBF mechanisms is critical. In particular, concerns regarding the potential for coercion when incentives are used with FP providers need to be carefully addressed in any research (Eichler et al. 2010). In addition, the effect of PBF programming on equity also needs to addressed, because the evidence available appears mixed (Hotchkiss 2011; Ravindram and Fonn 2011). Moreover, the relative cost-effectiveness of alternative PBF models is an important policy issue for which there is no firm evidence.

Many national governments have made substantial commitments to FP2020. It is likely, therefore, that traditional "input-based" financing for FP services through allocations from the countries' finance ministries is likely to continue to be the predominant model in the public sector. Evidence is needed, therefore, regarding how existing governmental financing mechanisms function and can be improvedfor example, through country-specific and meta analyses of national health accounts and other resource tracking methods.

The influence of price on the acceptability and use of different contraceptive methods is not clear. Definitive evidence regarding the price elasticity of contraceptive demand is still scarce, and much evidence tends to come from observational studies from the 1980s and 1990s. Most evidence indicates that contraceptive pricing is actually quite inelastic (Cleland et al. 2006), although income seems to be a factor in determining elasticity, implying that the poorest are more likely to be affected by user fees (DFID 2010a). More up-to-date rigorously designed studies are needed concerning the impact of user fees or out-of-pocket payments on contraceptive use and RH and potential equity impacts (DFID 2010a).

\section{Leadership and Governance}

The importance of political commitment as a determinant of demand for and use of FP cannot be overstated. Indeed, increasing such commitment is one of FP2020's four objectives. Trends in global and national support for FP are associated with trends in demand for and use of FP (Cleland et al. 2006; DFID 2010b). The stall in fertility decline in sub-Saharan Africa can be attributed in large part to ambiguous national will and reduced global commitment to FP throughout the 1990s and early 2000s (Bongaarts et al. 2012; Cleland et al. 2006), and recent rapid increases in FP use in several African 
countries can be attributed to increased political will (Murunga et al. 2012; USAID Africa Bureau 2012). Evidence supports the role of political commitment for increasing awareness of and demand for FP, as well as enhancing investments in and effective implementation of service delivery strategies to reduce unmet need (Jacobstein et al. 2013; Lee et al. 1998). Following the political and financial commitments made at the London FP Summit in July 2012, substantial investments will be made in advocacy efforts over the next few years to capitalize on these commitments. However, little evidence currently exists to guide investments in advocacy, to ensure that they are effective in increasing access, reducing unmet need, and addressing inequities. In addition to evaluations of recent and on-going advocacy initiatives (Murunga et al. 2012; USAID Africa Bureau 2012), prospective research is needed to evaluate the feasibility, implementation process, and effectiveness of forthcoming advocacy projects.

To ensure that these commitments translate into investments in a rights-based approach to reducing unmet need, FP2020 will be supporting mechanisms that hold governments, donors, and other organizations making and implementing the commitments accountable to the intended beneficiaries. Within the FP2020 architecture, both the Rights and Empowerment and Performance Monitoring and Accountability Working Groups will be responsible for ensuring accountability. They will require rigorous evidence to guide them in empowering communities, especially the most marginalized, to voice their needs and demand their entitlements, engage in decision-making to design and implement service delivery; and monitor potential rights abuses concerning FP provision. Accountability mechanisms do exist for FP, but evidence of their feasibility and effectiveness is limited primarily to case studies (Bongaarts et al. 2012; DFID 2010b; DFID 2010a). In anticipation of a rapid increase in accountability mechanisms, operations research to develop, test, and evaluate accountability interventions should be an urgent priority.

\section{Demand and Use Dynamics}

A thorough and context-specific understanding of the demand and use dynamics for FP is critical for planning to expand access to and reduce unmet need for FP through FP2020. Moreover, to ensure that all responses are rights-based and will contribute to universal access through reducing inequities, all analyses must disaggregate population-level data by the relevant social determinants for each country. The DHS provides substantial datasets from which many analyses of demand and use dynamics have been, and can be, undertaken. Given the scale of investment and the need to target interventions strategically for diverse populations, undertaking additional population-specific DHS-like surveys will probably be necessary to determine the specifics of such dynamics, especially for particularly vulnerable and poorly-documented populations.

In determining why many women with a demand for FP have an unmet need, understanding the reasons for non-use is an essential starting point. Unfortunately, the evidence base for understanding the reasons for non-use is still limited, due in part to an over-reliance on the evidence generated through the "reasons for non-use" questions used in the DHS. While useful if carefully interpreted, there is an urgent need for additional standardized measures that are able to describe the ambivalence women often feel concerning contraceptive use, their perceptions of various risks associated with use or non-use, and that can capture changes over time. Moreover, more nuanced and insightful interpretations of the responses given and their implications for investments in programming are needed. For example, in most developing countries, lack of access or high cost are no longer the primary reasons for non-use - infrequent sex and fear of side effects are the most commonly cited (Darroch et al. 2011), possibly because most investments in FP programming over the past two decades 
have been oriented towards reducing these barriers, and with apparent success. Future investment should be determined by the key reasons, disaggregated by population groups, within each country.

Recent evidence highlights the importance of and reasons for discontinuation, switching, and failure as factors determining unintended pregnancy and achievement of reproductive intentions (Ali, Cleland and Shah 2012). Indeed, one-third of unintended pregnancies occur among women who are using FP (i.e., have a met need). Better addressing the needs of women already using FP may be as effective a means of reducing unintended pregnancy as focusing on new users (Jain 1989). High rates of discontinuation (on average, around $40 \%$ at 12 months) stress the need to both ensure access to longer-acting effective methods, as well as improve service quality, particularly counseling, so that women can make an informed choice and are forewarned about side-effects and reassured about health concerns. Timely and informed method-switching needs to be better recognized to avoid unintended pregnancies, abortion, and unwanted or mistimed births. A lack of longitudinal data, especially prospectively collected, hinders better understanding of these important use dynamics.

One weakness of the DHS is that it does not adequately sample for adolescents and other non-married women, women living in vulnerable situations (e.g., sex workers, women living with HIV) and men. Although varying by country, these populations can suffer a significant proportion of the unmet need. Thus, more evidence is essential to understand contraceptive demand and use dynamics among these populations, either through strengthening the DHS or undertaking further population-specific surveys. For example, several countries have recently commissioned surveys of young people.

Determining whether a woman is using a method that is appropriate for her needs at a particular point in her life cycle, and whether there may be other, more suitable methods that are not available to her, is an important element of use dynamics that influences choice. It can also affect the likelihood of unintended pregnancy if she is using a less effective method because more effective options are not available, accessible, affordable, or acceptable. And it can potentially affect the cost of using and of providing contraceptives. Longer-acting methods generally cost less per couple year of protection (cost is amortized over longer term), than short-acting methods, and so a lack of access to such methods can increase costs to the woman and to the program. Information regarding the appropriateness of a method for a woman's reproductive intentions is critical for any market-shaping initiatives; thus, investments in generating such evidence would be extremely helpful.

\section{Associations between FP Use, Non-Use, and Distal Outcomes}

A central goal of family planning is to enable women to space and limit their children according to their own needs and desires. Family planning provides the means through which a woman's right to have children by choice and not by chance can be actualized. In addition, FP has important social, economic, environmental, and population implications. The associations between FP use and fertility, maternal, infant, and child health, population dynamics, economic development, poverty reduction, and food security are well-established after decades of research (Bongaarts et al. 2012; Bongaarts and Sinding 2011). This evidence is used primarily to advocate for political and financial commitment, which has proved essential in refocusing global and national attention on the adverse outcomes associated with unintended pregnancy and unwanted fertility. This evidence is also used for development planning by countries with emerging economies, as the integral role of population health and dynamics in poverty reduction and a country's economic and social growth is increasingly grasped by politicians and economists. 
Going forward, a continued investment in the generation and interpretation of demographic evidence remains critically important, especially in countries where the fertility transition is not yet complete and where important fluctuations in these relationships must be monitored. Moreover, in countries that could potentially benefit from a "demographic dividend" - when the working age population is increasing faster than the dependent population, leading to rapid economic growth (Cleland 2012) country-specific analyses that inform policymakers and politicians of how this dividend can be achieved would be important advocacy interventions and should be supported. A recent review of the likelihood of a demographic dividend in Africa cautions against expecting the same scale of dividend as those witnessed in East and South Asia unless the institutional setting is favorable, the economy is able to generate employment and provide education and health care for the increasing labor force, and household savings can lead to productive investments (Cleland 2012). Without these associated factors, rapidly increasing numbers of unemployed, poorly educated young people can lead to discontent and strife.

As the number of women in the reproductive age group increases because of population growth, so does the number of women needing contraceptive services and commodities. Thus for many developing countries seeking to increase access to FP, an important outcome is that the number of commodities required will increase dramatically due to the combination of increasing contraceptive prevalence and increasing population size; for example, between 2008 and 2012, an additional 42 million women were using contraceptives, half of which was due to population growth (Singh and Darroch 2012).

More recently, research on the associations between FP use, population growth (especially in urban populations and those living on coastal and desert fringes), the environment, and climate has become increasingly prominent and will continue to do so (Jiang and Hardee 2011). Although links between global climate patterns and a woman's right and means of having children by choice and not by chance may seem too distant to many, evidence from such analyses will become increasingly important for policy discussions and investment choices, especially in countries suffering from environmental degradation and problems meeting the food, water, and sanitation needs of their populations.

\section{Using Research, Monitoring, and Evaluation for Guidance Development}

The scientific evidence that informed this review draws from data collected through numerous methodologies and from a variety of sources. Broadly speaking, these can be categorized into: a) Research studies using social science methods to collect and analyze quantitative or qualitative data using designs that seek to maximize the validity and reliability of the findings (including, for example, the DHS); b) Formal evaluations of the feasibility, acceptability, cost, and effectiveness of service delivery and system strengthening interventions that seek to increase access to and use of FP; c) HMISs that routinely monitor systems performance in delivering FP information and services.

Much of the focus in this review has been on research to improve health systems. The past decade has seen a burgeoning of research strategies, approaches and methods being applied to generate evidence to influence decisions around health systems strengthening; indeed, global conferences on health systems research held in 2010 and 2012 attest to the sheer scale of research being undertaken. An unfortunate consequence has been the plethora of definitions and terms that have been developed and applied to this research, resulting in confusion and misunderstandings, not least among research donors and researchers themselves. A review and framing of the key domains (operational, implementation, health 
systems) that comprise research to improve health systems (Remme et al. 2010) provides a useful starting point from which research donors and researchers can understand and agree upon definitions and categories of research for framing and organizing future research investments.

Evidence for informing strategic investments to increase access to FP derives primarily from formal evaluations of intervention feasibility and effectiveness, although those responsible for making such investment decisions are increasingly seeking evidence of an intervention's impact on quality of care, on universal access and equity, and on its sustainability. Evidence of effectiveness is usually considered to be of highest quality, and so can provide the strongest recommendations for action, if it is derived from a randomized controlled trial (RCT). As this review found, RCTs are rarely undertaken in FP research for numerous reasons: they may be too costly; they may not be ethically or practically feasible; or they may produce evidence that is not programmatically useful. While recognizing the theoretical strength of these "probability" designs, the role of "plausibility" designs in generating evidence that is of acceptable quality to decision-makers and can be used to make strong recommendations is gaining acceptance (BoschCapblanch and Team 2011; Victora, Habicht and Bryce 2004). Such designs are often quasi-experimental and use multiple methods and sources to generate data that provides a plausible, rather than statistically probable, attribution of effect to the intervention being evaluated.

Recommendations for expanding access to FP that derive from research-based evidence are frequently framed as service delivery 'guidelines' or systems strengthening 'guidance', defined in a WHOcommissioned handbook as "the systematically developed body of knowledge, integrating research evidence and descriptions of the types of other considerations needed to inform decision making about appropriate health system arrangements in specific settings" (Bosch-Capblanch 2011); The handbook proposes a rigorous and systematic process for reviewing and using research-based evidence for health systems guidance and policymaking (BoschCapblanch et al. 2012; Lavis et al. 2012; Lewin et al. 2012).

What qualifies as high quality "evidence" and what is a "best" or "proven" implementation practice remains open to debate, however. Other approaches to reviewing and synthesizing evidence and formulating guidance have accepted evidence from non-RTC designs and more experiential evidence, for example DFID's series of "evidence reviews" on Reproductive, Maternal and Newborn Health, and USAID's "High Impact Practices in Family Planning (HIPs)". Lack of agreement on the criteria for evidence quality and its use in the formulation of policy and programmatic recommendations, especially at the global level, will

\section{Evidence Gaps: Areas for Research Investment}

Approaches to Determining Inequities and Identifying Needs of Underserved and Vulnerable Populations

Methodologies to Prospectively Evaluate Structural Interventions to Reduce Inequities and Vulnerability

Interventions to Meet the Needs of Unmarried and Married Adolescents

Interventions to Improve and Sustain the Quality of FP Services

Strategies for Scaling up Effective Models of Integrated Services

Strategies for Reaching Rural Communities

Strategies for Reaching Urban Poor Populations

Techniques for Defining and Shaping Contraceptive Markets to Improve Availability and Access

Innovative Financing Mechanisms to Expand Access and Increase Affordability

Strategies for Advocacy and Accountability

Understanding the Dynamics of Contraceptive Decision-Making and Use

Building Capacity and Improving Methods to Generate and Use Evidence on FP 
inhibit FP2020's ability to introduce and expand effective interventions for reducing unmet need; achieving such consensus is an urgent priority.

\section{Research Gaps}

This review shows that a substantial body of evidence concerning the determinants, outcomes and dynamics of contraceptive use and unmet need has been, and continues to be, generated through a range of research and evaluation activities. Prior investments over several decades in research and evaluation, including building capacity to produce and use research-based evidence, has yielded an impressive body of knowledge that has guided the development and expansion of FP information and services in many developing countries.

The commitments made at the London FP Summit, and the establishment of the FP2020 initiative to implement these, require that many developing countries will need to rapidly and efficiently increase the scale and intensity of existing FP delivery systems, while simultaneously expanding the number and diversity of public and non-public sector markets through which FP can be accessed by those needing FP services. The evidence base to guide how best to do this is, however, lacking in several key areas, as described above. The following evidence gaps warrant consideration for immediate investment in research and in building research capacity.

\section{Approaches to Determining Inequities and Identifying Needs of Underserved and Vulnerable Populations}

Although the social determinants of FP demand and use are well understood, how these function in specific national and sub-national contexts must to be clearly mapped if countries are to implement rights-based approaches to reducing unmet need. For many countries, population-level surveys, in addition to or as a component of a regular DHS, that are designed to more precisely determine inequities in access to and use of FP are needed urgently to inform programming, policy and, importantly, budgetary allocations and investments within a country's FP2020 plan. Using these surveys as a baseline, they should be repeated regularly to detect and monitor whether reductions in inequities are occurring and whether underserved and vulnerable populations are being reached.

Such research should proactively engage those often excluded in routine surveys, such as married and unmarried girls and boys, sex workers, migrants, and indigenous and slum populations. In-depth analyses should also be conducted to determine the specific needs of vulnerable and underserved populations and to identify targeted interventions that would increase their access and empower them to hold the health system accountable. This evidence would also provide countries the opportunity to provide "voice" to its vulnerable groups so that they can actively engage in FP programming.

\section{Methodologies to Prospectively Evaluate Structural Interventions to Reduce Inequities and Vulnerability}

The importance of structural determinants in limiting access and use of FP is well-understood; much more evidence is needed, however, of the feasibility and effectiveness of interventions that can reduce the inequities and vulnerabilities that they cause. Evidence of the effectiveness of interventions that reduce early marriage, reduce unmarried girls' exposure to unwanted and coerced sex, and empower women to meet their reproductive intentions is largely non-existent. Evidence is also needed concerning "gendered" interventions that enable more positive and balanced interactions by girls and women with their partners, families, and communities. Prospective, rigorously designed impact evaluations of multi- 
faceted structural interventions are needed. Although requiring substantial investments of time and funding, they would generate evidence that would not only increase FP use but also improve social relations, gender dynamics, and women's and girls' rights more widely.

\section{Interventions to Meet the Needs of Unmarried and Married Adolescents}

Adolescent girls and boys, both married and unmarried, form substantial proportions of those with unmet need; moreover, they are often among the most vulnerable and underserved of populations and their needs for appropriate sexuality education are often as great as their need for contraceptives. However, despite the evidence generated through many and varied initiatives over the past two decades, context-specific research is critical if countries are to better understand the needs, preferences and circumstances of the many and extremely varied groups of adolescents that exist in all societies. The diversity of "adolescence" cannot be overemphasized, and so combinations of social science and operations research are needed to first diagnose the varied needs of different adolescent groups and to then test and scale-up sustainable strategies that are appropriate for addressing the educational, informational and service needs of the different adolescents. Moreover, national HMISs urgently need to be strengthened so as to collect, analyze, and use data disaggregated by age and other critical determinants of adolescents' FP needs.

\section{Interventions to Improve and Sustain the Quality of FP Services}

FP2020 recognizes and endorses all individuals' right to the highest quality of care; moreover, existing evidence indicates that poor-quality counseling and delivery are universal barriers to initiation and sustained use of FP. More evidence is needed to identify feasible and acceptable interventions that enable and require providers to respond to their clients' individual needs. Evidence is also needed of their effectiveness and sustainability in both attracting new FP users and in reducing discontinuation, as well as their ability to ensure that the distinct needs of vulnerable and underserved populations are appropriately met. Investment in context-specific operations and implementation research around quality improvement interventions would enable health systems to address the many method-and programrelated factors that are the most commonly cited reasons for non-use of contraception among women with an unmet need. A key research investment would be the strengthening of quality assurance and monitoring mechanisms to ensure that such improvements are standardized, routinized, and sustained.

\section{Strategies for Scaling up Effective Models of Integrated Services}

Integrating FP within other health services is an important strategy for FP2020; integrated services can be more accessible, acceptable, affordable and less stigmatized, and there may be greater efficiencies in service delivery. Evidence of the feasibility, acceptability and effectiveness of various models of FP integration with antenatal, delivery, postpartum and postabortion care, and with HIV services, is wellestablished. Evidence of how to adapt, scale-up, and institutionalize these models within a national health system is lacking, however, in part because there is little experience of offering integrated services at scale. Prospective implementation research is needed that systematically documents strategies for scaling up various proven models through describing the systems-level organizational modifications (e.g. in commodity supplies, provider training and supervision, M\&E, etc.), policy adjustments, budgetary reallocations, and the costs and cost-savings involved when expanding an integrated model proven through a small-scale pilot study. 


\section{Strategies for Reaching Rural Communities}

Many developing countries are still characterized by largely rural, often remote, populations. Evidence supports the effectiveness of CHW programs in expanding access to FP among these populations and so expansion of such programs is likely to feature significantly in many national FP2020 initiatives.

Countries would benefit, however, from investments in operations and implementation research that would enable them to fine-tune this proven best practice to their national contexts and to rapidly roll-out coverage to better reach underserved and vulnerable populations. CHWs can also be important strategies for reaching populations living in urban informal or 'slum' settlements. Greater investment in policy analyses and health systems research would guide countries in incorporating community-level services into the formal health system, especially countries seeking to adapt national models that have been proven effective by NGOs or faith-based organizations (FBOs).

Existing evidence also supports investment in expansion of a second proven strategy for reaching rural communities, that is, mobile outreach services, which can be an essential source of long-acting reversible and permanent contraception, thereby complementing the delivery of short-acting methods that characterizes most CHW programs. However, investment in operations and implementation research would help countries to rapidly adapt this strategy in both public and non-public programs.

\section{Strategies for Reaching Urban Poor Populations}

Rapid urbanization is leading to burgeoning populations of urban poor that are often more disadvantaged and have poorer reproductive and maternal health than the rural poor. Despite geographical proximity to a wide range of outlets, access to affordable and appropriate services is often constrained. Evidence-based strategies for reaching the rapidly growing urban poor will be critical for FP2020, given the scale of growth in these populations and the increasing share the urban poor will contribute to unmet need. Private sector pharmacies, drug sellers, and commercial retail outlets—either independently or within a social marketing program-have tremendous potential to complement public (and private) facilities in urban areas, but evidence of feasibility, affordability, quality of care, and effectiveness in engaging with the private sector to reach the urban poor are lacking. A "total market" approach, including a range of research activities to assess and analyze the situation and opportunities, would be particularly appropriate when planning and developing strategies to reach the full spectrum of slum dwellers.

\section{Techniques for Defining and Shaping Contraceptive Markets to Improve Availability and Access}

Market shaping will feature prominently in FP2020 and is a process that requires much more evidence of contraceptive demand and use dynamics and of commodity market dynamics than is currently available or than can be generated with existing research methods. Developments in research methods are needed urgently, by drawing initially from the experiences of organizations and donors undertaking market shaping in other health fields (e.g. HIV, malaria) and adapting these techniques to contraceptive market development approaches. Investments in building the capacity of FP researchers to understand and apply these methods, and of health system planners to understand and use the data generated from market shaping analyses, are needed immediately if this key element of FP2020 is to be successful. 


\section{Innovative Financing Mechanisms to Expand Access and Increase Affordability}

The impressive commitments of financial and other resources for FP2020 can only be successful if the systems in which they are invested function efficiently and ensure that a full range of affordable contraceptive options are available to as wide a population as possible. PBF is emerging as a potential complement to conventional input-based public-sector financing for health systems generally, but little evidence exists concerning PBF of FP services. Investment in operations and implementation research to evaluate and compare the cost, effectiveness and equity effects of various PBF models in the public and non-public sectors with conventional input-based financing models is essential and urgently needed. As most national health systems will continue to finance FP services through input-based financing, however, (at least during the lifetime of FP2020), research is also needed to better understand these financing mechanisms and to identify interventions to improve their functioning and efficiency.

As contraceptive markets continue to diversify, the price of contraceptive commodities, both to governments and to users, will become an increasingly important factor. Further evidence is needed, which can be researched with existing methods, about users' willingness and ability to pay, and about the role of method pricing in determining access for vulnerable and marginalized populations as well as the method mix available, especially in public sector programs.

\section{Strategies for Advocacy and Accountability}

Two major and interrelated thrusts of FP2020, for which clear conceptualizations are lacking and there is little research-based evidence of what is effective, are interventions for advocacy (to ensure that commitments are actually made and invested appropriately) and for accountability (to empower communities to engage meaningfully in FP2020-supported initiatives and to institutionalize this engagement). Given the centrality to the objectives of FP2020 of both advocacy and accountability, investments in developing an evidence base for both types of interventions should be an urgent priority. Case studies of existing experiences, operations research that develops and tests various interventions, and rigorous $M \& E$ mechanisms to document their implementation and assess their impact would be helpful in building this evidence base.

\section{Understanding the Dynamics of Contraceptive Decision-Making and Use}

To reduce unmet need effectively, a national program first needs to fully understand the reasons why women, girls, and their partners do or do not use contraception when they are at risk of an unintended pregnancy, and how these reasons vary among different population groups. Country-specific social science research is needed to analyze these reasons and their determining factors so as to identify which delivery strategies, financing mechanisms, demand generation strategies or commodity mix options would best address the various barriers to use, disaggregated by key population groups. Moreover, methodological developments are needed to better measure and explain socio-behavioral determinants of demand and use, including risk perception, ambivalence, and fear, both for the women and their partners. This research is particularly needed in settings and for populations marked by low literacy rates, poverty, and low contraceptive prevalence.

Recent evidence reinforces the major contribution to unmet need and unintended pregnancy of discontinuation and method failure or inconsistent/incorrect use of contraceptives. Context-specific social science and acceptability research are needed to inform programs of the reasons for method discontinuation or failure so that interventions can be developed and tested through operations research to reduce the causative factors. Such evidence can also inform market shaping (to identify appropriate method mixes for particular populations) and product development (to guide new product designs). 


\section{Building Capacity and Improving Methods to Generate and Use Evidence on FP}

The human resources needed to undertake the research that will address these evidence gaps remains highly concentrated in northern countries and organizations; a substantial and immediate investment in building southern-based research capacity is critical if evidence generation is to be institutionalized and sustained in the countries that need the evidence. Moreover, some evidence gaps will need new or adapted measures and research methods, which will require investment in their development, validation, and testing in a variety of contexts. Additionally, despite the heavy reliance on national HMISs for data to evaluate FP services, virtually all HMISs in developing countries generate data of dubious validity; investment is urgently needed to strengthen HMISs in most developing countries, especially through computerization, as well as the capacity of program managers to extract and use the data reported.

While increasing emphasis on evidence-informed decision-making by donors and national health systems is welcomed and strongly endorsed, the capacity of decision-makers, in both developing and developed countries, to interpret and use research-based evidence is mixed. In particular, there is much confusion and a lack of agreement about procedures for collating and synthesizing evidence from various sources, including research, for formulating recommendations for programming. For guidance in "best practices" to be recommended, there needs to be greater consensus among decision-makers, especially in donor and policymaking organizations, on what constitutes high-quality evidence and which types of evidence provide the greatest degree of confidence for making strong recommendations. Uncertainty over the credibility of evidence not generated through RCTs and the role of experiential evidence are just two of the factors confusing the role of evidence in programmatic recommendations.

\section{Looking Ahead}

Research shows that through high-quality voluntary FP programs, governments can reduce fertility and generate substantial improvements in health, wealth, human rights, and education. Family planning programs for the $21^{\text {st }}$ century will require thoughtful design-engaging both public and private sectorsto meet the growing need for safe and effective FP services. Moreover, the combination of substantial commitments to FP2020 from national governments and a wide range of development partners presents a major challenge in coordinating efforts by multiple actors with different expectations and ways of functioning.

A new generation of women and men will be entering their reproductive years during FP2020; they represent future global markets, future parents, and future FP users. Efforts to provide timely, accurate, and culturally appropriate information can contribute to the RH of many. The challenges ahead for FP programs will be to increase overall access while reducing inequities in individuals' ability to use a method of their choice, particularly inequities due to poverty, gender, age, and marital status. This requires investments in research that not only informs health systems strengthening but also empowers girls and women to make and act upon their own best decisions about pregnancy and childbearing. These challenges need to be addressed in the context of constantly increasing population sizes in most developing countries, necessitating additional investments just to sustain existing levels of need.

We must seize the moment and "capitalize on the growing momentum to establish family planning programs as accepted, expected, and routine elements of national health care systems worldwide" (Bongaarts et al. 2012). 


\section{Glossary of Terms and Definitions}

\section{Contraceptive prevalence}

The percentage of women who are currently using, or whose sexual partner is currently using, at least one method of contraception, regardless of the method used. It is usually reported for married or inunion women aged 15 to 49.

(http://www.who.int/reproductivehealth/topics/family planning/contraceptive prevalence/en/)

Market development approaches (MDAs) to reproductive health are initiatives that work toward enhanced financial sustainability, improved access and expanded choice. The term "market development approach" encompasses a very broad set of approaches to health care delivery, but by definition involves the commercial sector.

\section{Market shaping}

Market shaping (in this context) is defined as supporting the efficient procurement of quality commodities while ensuring sustainable supply at affordable prices to eligible countries. (http://www.gavialliance.org/library/gavi-documents/white-papers/market-shaping--strategicconsiderations-for-a-healthy-vaccine-marketplace

\section{Market segmentation}

Market segmentation is the process of dividing the total market into smaller subsets (segments) that have similar characteristics, needs, or behaviors. Market segmentation analysis looks at current patterns of demand and use for RH commodities and the characteristics of users-socioeconomic, sociocultural, and behavioral-in order to find better and more efficient ways to meet existing demand or generate increased demand. (http://deliver.jsi.com/dhome/topics/policy/csinitiatives/marketsegmentation

Market segmentation strategies are used by businesses to divide their customers into distinct groups based on different factors, such as income, and to target their products accordingly. In FP, market segmentation is used to divide the FP market into groups based on choice of method and provider and to match clients with sources based on need and ability to pay.

http://www.fhi.org/en/RH/Pubs/booksReports/fpfinancing/brief3.htm

\section{Population momentum}

The tendency for population growth to continue beyond the time that replacement-level fertility has been achieved because of the relatively high concentration of people in the childbearing years. (http://www.prb.org/Educators/Resources/Glossary.aspx)

\section{Social determinants}

The social determinants of health are the conditions in which people are born, grow, live, work and age, including the health system. These circumstances are shaped by the distribution of money, power and resources at global, national and local levels. The social determinants of health are mostly responsible for health inequities - the unfair and avoidable differences in health status seen within and between countries. (http://www.who.int/social determinants/en/)

Inter-related social and economic factors that influence health. Social determinants of health include, but are not limited to: socioeconomic status, discrimination, housing, physical environment, food security, 
child development, culture, social support, healthcare services, transportation, working conditions, and democratic participation.

\section{Structural interventions}

Structural interventions refer to public health interventions that promote health by altering the structural context within which health is produced and reproduced. Structural interventions differ from many public health interventions in that they locate, often implicitly, the cause of public health problems in contextual or environmental factors that influence risk behavior, or other determinants of infection or morbidity, rather than in characteristics of individuals who engage in risk behaviors.

(http://www.ncbi.nlm.nih.gov/pmc/articles/PMC1473169/)

Interventions designed to remove barriers and incorporate facilitators of an individual's HIV prevention (health-seeking, disease prevention) behaviors. These barriers or facilitators include physical, social, cultural, organizational, community, economic, legal, or policy circumstances or actions that directly or indirectly affect an individual's ability to avoid (disease, poor health) exposure to HIV. (http://www.cdc.gov/hiv/topics/evaluation/health depts/guidance/glossary.htm)

Structural approaches include social, economic, and political interventions that can improve public health outcomes by increasing the willingness and ability of individuals to practice prevention. http://www.aidstarone.com/focus areas/prevention/pkb/structural interventions/overview stru ctural approaches hiv prevention)

\section{Total fertility rate}

The number of children who would be born per woman (or per 1,000 women) if she/they were to pass through the childbearing years bearing children according to a current schedule of age-specific fertility rates. The TFR is the most widely used fertility measure in program impact evaluations for two main reasons: (1) it is unaffected by differences or changes in age-sex composition, and (2) it provides an easily understandable measure of hypothetical completed fertility. (http://www.cpc.unc.edu/measure/prh/rh_indicators/specific/fertility/total-fertility-rate)

The average number of live births a woman would have by age 50 if she were subject, throughout her life, to the age-specific fertility rates observed in a given year. Its calculation assumes that there is no mortality. (http://www.un.org/esa/sustdev/natlinfo/indicators/methodology sheets/demographics/ total fertility rate.pdf)

\section{Total market approach}

Having the public and nonprofit sectors provide subsidized services for needy consumers while maintaining sustainable commercial provision for consumers who are able to pay is often referred to as a "total market" or "whole market" approach. (http://www.rhsupplies.org/fileadmin/user upload/MDA Documents/Total Market Initiatives f or Reproductive Health.pdf)

DFID defines a TMA as a process to "assess the characteristics of existing and likely future markets, and to define the comparative advantage of commercial, social marketing, non-governmental organization, and public sector actors in terms of competence and value for money in delivering a range of products or services to different market segments, including the poorest. It can enable closer and more structured linkages with commercial, public and non-governmental organizational sectors and aid 
the gradual shifting of consumers with sufficient purchasing power out of the public sector." (http://shopsproject.org/sites/default/files/resources/5010 file Total Market Approach honey manp3.pdf

\section{Unmet need}

The percent with an unmet need for family planning is the number of women with unmet need for family planning expressed as a percentage of women of reproductive age who are married or in a union. Women with unmet need are those who are fecund and sexually active but are not using any method of contraception, and report not wanting any more children or wanting to delay the birth of their next child. (http://www.who.int/reproductivehealth/topics/family planning/unmet need fp/en/index.html)

\section{Youth bulge}

A high proportion of 15-to-29 year olds relative to the adult population.

(http://blogs.worldbank.org/developmenttalk/youth-bulge-a-demographic-dividend-or-ademographic-bomb-in-developing-countries)

The youth bulge is a common phenomenon in many developing countries, and in particular, in the least developed countries. It is often due to a stage of development where a country achieves success in reducing infant mortality but mothers still have a high fertility rate. The result is that a large share of the population is comprised of children and young adults, and today's children are tomorrow's young adults. (http://blogs.worldbank.org/developmenttalk/youth-bulge-a-demographic-dividendor-a-demographicbomb-in-developing-countries) 


\section{REFERENCES}

Ali, M., et al. 2012. "Reducing unmet need for family planning: Results of a global research priority setting exercise," presented at Family Planning Research Donor Meeting, Washington, DC, 3-4 December 2012.

Ali, M.M., J. Cleland, and I.H. Shah. 2012. Causes and Consequences Of Contraceptive Discontinuation: Evidence from 60 Demographic and Health Surveys. Geneva: World Health Organization.

Barnes, J., J. Vail, and D. Crosby. 2012. Total Market Initiatives for Reproductive Health. Bethesda, MD: Abt Associates.

Bongaarts, J., J. Cleland, J.W. Townsend, J.T. Bertrand, and M.D. Gupta. 2012. Family Planning Programs for the 21st Century. Rationale and Design. New York: The Population Council, Inc.

Bongaarts, J., and S. Sinding. 2011. "Population policy in transition in the developing world." Science 333(6042):574-576.

Bosch-Capblanch, X. 2011. Handbook for Supporting the Development of Health System Guidance. Basel, Switzerland: Swiss Centre for International Health.

Bosch-Capblanch, X., J. Lavis, S. Lewin, R. Atun, and J. Røttingen. 2012. "Guidance for evidenceinformed decisions about health systems: Rationale for and challenges of guidance development." PLoS Med 9:e1001185.

Bosch-Capblanch, X., and Project Team. 2011. Handbook for Developing Health Systems Guidance: Supporting Informed Judgments for Health Systems Policies. Basel: Swiss Tropical and Public Health Institute.

Bruce, J. 1990. "Fundamental elements of the quality of care: A simple framework." Studies in Family Planning 21(2):61-91.

Chapman, S., and H. Astatke. 2003. Review of DFID Approach to Social Marketing. Annex 5: Effectiveness, Efficiency and Equity of Social Marketing and Appendix to Annex 5: The Social Marketing Evidence Base. London, UK: DFID Health Systems Resource Centre.

Church, K., and S. Mayhew. 2009. "Integration of STI and HIV prevention, care, and treatment into family planning services: A review of the literature." Studies in Family Planning 40(3):171-186.

Cleland, J. 2012. Will Africa Benefit from a Demographic Dividend? Oxford, UK: Oxford Policy Management.

Cleland, J., S. Bernstein, A. Ezeh, A. Faundes, A. Glasier, and J. Innis. 2006. "Family planning: The unfinished agenda." The Lancet 368(9549):1810-1827.

Creanga, A.A., D. Gillespie, S. Karklinsa, and A.O. Tsui. 2011. "Low use of contraception among poor women in Africa: An equity issue." Bull World Health Organ 89:258-266.

Darroch, J., G. Sedgh, and H. Ball. 2011. Contraceptive Technologies: Responding to Women's Needs. New York: Guttmacher Institute.

DFID. 2010a. Improving Reproductive, Maternal and Newborn Health: Burden, Determinants and Health Systems. Evidence Overview. Working Paper (Version 1.0). London, UK: DFID.

DFID. 2010b. Improving Reproductive, Maternal and Newborn Health: Reducing Unintended Pregnancies. Evidence Overview. Working Paper (Version 1.0). London, UK: DFID.

Eichler, R., B. Seligman, A. Beith, and J. Wright. 2010. Performance-Based Incentives: Ensuring Voluntarism in Family Planning Initiatives. Bethesda: Health Systems 20/20 Project, Abt Associates Inc. 
Gillespie, D., S. Ahmed, A. Tsui, and S. Radloff. 2007. "Unwanted fertility among the poor: an inequity?" Bulletin of the World Health Organization 85:100-107.

Gipson, J., M. Koenig, and M. Hindin. 2008. "The effects of unintended pregnancy on infant, child, and parental health: A review of the literature." Studies in Family Planning 39(1):18-38.

Haberland, N. 2003. "The neglected majority: Married adolescents," in Adolescent and Youth Sexual and Reproductive Health: Charting Directions for a Second Generation of Programming; Background Document for UNFPA Workshop, May 1-3 2002. New York: Population Council.

Halpern, V., L. Lopez, D. Grimes, and M. Gallo. 2011. "Strategies to improve adherence and acceptability of hormonal methods of contraception." Cochrane Database of Systematic Reviews 2011 (4):CD004317.

Hiller, J., E. Griffith, and F. Jenner. 2007. "Education for contraceptive use by women after childbirth." Cochrane Database of Systematic Reviews 2002 (3):CD001863.

Hindin, M.J., C.S. Christiansen, and B.J. Ferguson. 2013. "Setting research priorities for adolescent sexual and reproductive health in low- and middle-income countries." Bulletin of the World Health Organization 91:10-18 (Article ID: BLT.12.107565).

Hossain, S.M.I., et al. 2009. ECP Handbook: Introducing and Mainstreaming the Provision of Emergency Contraceptive Pills in Developing Countries. Washington, DC: FRONTIERS, Population Council.

Hotchkiss, D. 2011 "Effect of an expansion in private sector provision of contraceptive supplies on horizontal inequity in modern contraceptive use: Evidence from Africa and Asia." International Journal for Equity in Health 10(1):33.

Jacobstein, R., C. Curtis, J. Spieler, and S. Radoff. 2013. "Meeting the need for modern contraception: Effective solutions to a pressing global challenge." International Journal of Gynecology and Obstetrics. http://dx.doi.org/10.1016/j.ijgo.2013.02.005.

Lee, K., L. Lush, G. Walt, and J. Cleland. 1998. "Family planning policies and programmes in eight low-income countries: A comparative policy analysis." Social Science and Medicine 47:949-959.

Jain, A. 1989. "Fertility reduction and the quality of family planning services." Studies in Family Planning 20(1):1-16.

Jain, A. 2001. "Family planning programs: Quality of care," in The International Encyclopedia of the Social and Behavioral Sciences, edited by N.J. Smelser and P.B. Baltes. Amsterdam: Elsevier.

Jain, A. 2012. "Quality of care," prepared for USAID/UNFPA-sponsored meeting on "High Impact Practices in Family Planning," 9 July 2012, New York.

Jiang, L., and K. Hardee. 2011. "How do recent population trends matter to climate change?" Population Research and Policy Review 30:287-312.

Johnson, R., S. Ndhlovu, S. Farr, and T. Chipato. 2002. "Reducing unplanned pregnancy and abortion in Zimbabwe through postabortion contraception." Studies in Family Planning 33:195-202.

Keesbury, J., and J. Thompson. 2010. A Step-by-Step Guide to Strengthening Sexual Violence Services in Public Health Facilities: Lessons and Tools from Sexual Violence Services in Africa. Lusaka: Population Council.

K4Health. 2012. http://hips.k4health.org/. Accessed February 27, 2013.

L'Engle, K. 2013. "Evaluating feasibility, reach and potential impact of a text message family planning information service in Tanzania." Contraception 87(2):251-256. 
Lavis, J., J. Røttingen, X. Bosch-Capblanch, R. Atun, and F. El-Jardali. 2012. "Guidance for evidenceinformed policies about health systems: linking guidance development to policy development." PLoS Med 9:e1001187.

Lee, K., L. Lush, G. Walt, and J. Cleland. 1998. "Family planning policies and programmes in eight low-income countries: A comparative policy analysis." Social Science and Medicine 47:949-959.

Lee-Rife, S., A. Malhotra, A. Warner, and A.M. Glinski. 2012. "What works to prevent child marriage: A review of the evidence." Studies in Family Planning 43(4):287-303.

Lewin, S., X. Bosch-Capblanch, S. Oliver, E. Akl, and G. Vist. 2012. "Guidance for evidence informed decisions about health systems: Assessing how much confidence to place in health systems evidence." PLoS Med 9:e1001187.

Lundgren, R. 2012. "Assessing the effect of introducing a new method into family planning programs in India, Peru, and Rwanda." Reproductive Health 9(17).

Madhavan, S., and D. Bishai. 2010. Private Sector Engagement in Sexual and Reproductive Health and Maternal and Neonatal Health A Review of the Evidence. Baltimore: Department of Population, Family, and Reproductive Health, Johns Hopkins Bloomberg School of Public Health.

Malarcher, S., O. Meirik, E. Lebetkin, I. Shah, J. Spieler, and J. Stanback. 2011. "Provision of DMPA by community health workers: What the evidence shows." Contraception 83:495-503.

MCHIP. 2012. Synthesis of Postpartum Family Planning Program Literature. Washington, D.C.: Maternal and Child Health Integrated Program (MCHIP).

Murunga, V., N. Musila, R. Oronje, and E. Zulu. 2012. Africa on the Move! The Role of Political Will and Commitment in Increasing Access to Family Planning in Africa. Washington, DC: The Wilson Center.

Mwaikambo, L., I.S. Speizer, A. Schurmann, G. Morgan, and F. Fikree. 2011. "What works in family planning interventions: A systematic review." Studies in Family Planning 42(2):67-82.

Ortayli, N., and S. Malarcher. 2010. "Equity analysis: Identifying who benefits from family planning programs." Studies in Family Planning 41(2):101-108.

Phillips, J., W. Greene, and E. Jackson. 1999. Lessons from Community-based Distribution of Family Planning in Africa. New York: Population Council.

RamaRao, S., and R. Mohanam. 2003. "The quality of family planning programs: Concepts, measurements, interventions, and effects." Studies in Family Planning 34(4):227-248.

Ravindram, S., and S. Fonn. 2011. "Are social franchises contributing to universal access to reproductive health services in low-income countries?" Reproductive Health Matters 19(38):85-101.

Remme, J., T. Adam, F. Becerra-Posada, C. D’Arcangues, M. Devlin, et al. 2010. "Defining research to improve health systems." PLoS Med 7(11): e1001000.

Reynolds, H., B. Janowitz, R. Wilcher, and W. Cates. 2008. "Contraception to prevent HIV-positive births: Current contribution and potential cost-savings in PEPFAR countries." Sexually Transmitted Infection 84 (Suppl II):ii49-ii53.

Singh, S., and J. Darroch. 2012. Adding it up: Costs and Benefits of Contraceptive Services-Estimates for 2012. New York: Guttmacher Institute and United Nations Population Fund.

Spaulding, A., D. Brickley, and C. Kennedy. 2009. "Linking family planning with HIV/AIDS interventions: A systematic review of the evidence." AIDS 23 (Suppl 1):S79-S88. 
Speizer, I., R. Magnani, and C. Colvin. 2003. "The effectiveness of adolescent reproductive health interventions in developing countries: a review of the evidence." Journal of Adolescent Health 33(5):324-348.

Stephenson, R., A.O. Tsui, S. Sulzbach, P. Bardsley, G. Bekele, T. Giday, R. Ahmed, G.

Gopalkrishnan, and B. Feyesitan. 2004. "Franchising reproductive health services." Health Services Research 39(6, part 2):2053-2080.

Tripney, J., K.S. Bird, I. Kwan, and J. Kavanagh. 2011. The Impact of Post-abortion Care Family Planning Counselling and Services in Low-income Countries: A Systematic Review of the Evidence. London, UK: EPPICentre, Social Science Research Unit, Institute of Education, University of London, 90 pp.

Tripney, J., I. Kwan, and K.S. Bird. 2013. "Postabortion family planning counseling and services for women in low-income countries: A systematic review." Contraception 87(1):17-25.

USAID. Unpublished-a. Drug Shops and Pharmacies: Important Sources for Family Planning Commodities and Information. High Impact Practices in Family Planning (HIPs) brief. Washington, DC: USAID.

USAID. Unpublished-b. Mobile Outreach Services: Expanding Access to Long-acting and Permanent Methods. High Impact Practices in Family Planning (HIPs) brief. Washington, DC: USAID.

USAID. 2012a. Community Health Workers: Bringing Family Planning Services to Where People Live and Work. High Impact Practices in Family Planning (HIPs) brief. Washington, DC: USAID.

USAID. 2012b. Postabortion Family Planning: Strengthening the Family Planning Component of Postabortion Care. High Impact Practices in Family Planning (HIPs) brief. Washington, DC: USAID.

USAID Africa Bureau. 2012. Three Successful Sub-Saharan Africa Family Planning Programs: Lessons for Meeting the MDGs. Washington, DC: USAID.

Vernon, R. 2009. "Meeting the family planning needs of postpartum women." Studies in Family Planning 40(3):235-245.

Victora, C., J. Habicht, and J. Bryce. 2004. "Evidence-based public health: Moving beyond randomized trials." Am J Public Health 3:400-405.

Westoff, C.F., D.A. Koffman, and C. Moreau. 2011. "The impact of television and radio on reproductive behavior and on HIV/AIDS knowledge and behavior." Calverton, Maryland: ICF International.

WHO. 2011. Guidelines on Preventing Early Pregnancy and Poor Reproductive Health Outcomes among Adolescents in Developing Countries. Geneva, Switzerland: WHO.

WHO. 2012a. Hormonal Contraception and HIV: Technical Statement. Geneva, Switzerland: WHO.

WHO. 2012b. Recommendations for Optimizing Health Worker Roles to Improve Access to Key Maternal and Newborn Health Interventions through Task Shifting. Geneva, Switzerland: WHO.

WHO. 2012c. From Evidence to Policy: Expand Access to Family Planning -Improve Contraceptive Services for Adolescents. Geneva, Switzerland: WHO.

Wilcher, R., W. Cates, and S. Gregson. 2009. "Family planning and HIV: Strange bedfellows no longer." AIDS 23(Suppl I):S1-6.

Witter, S., A. Fretheim, F. Kessy, and A. Lindahl. 2012. "Paying for performance to improve the delivery of health interventions in low-and middle-income countries." Cochrane Database of Systematic Reviews (2):CD007899. 


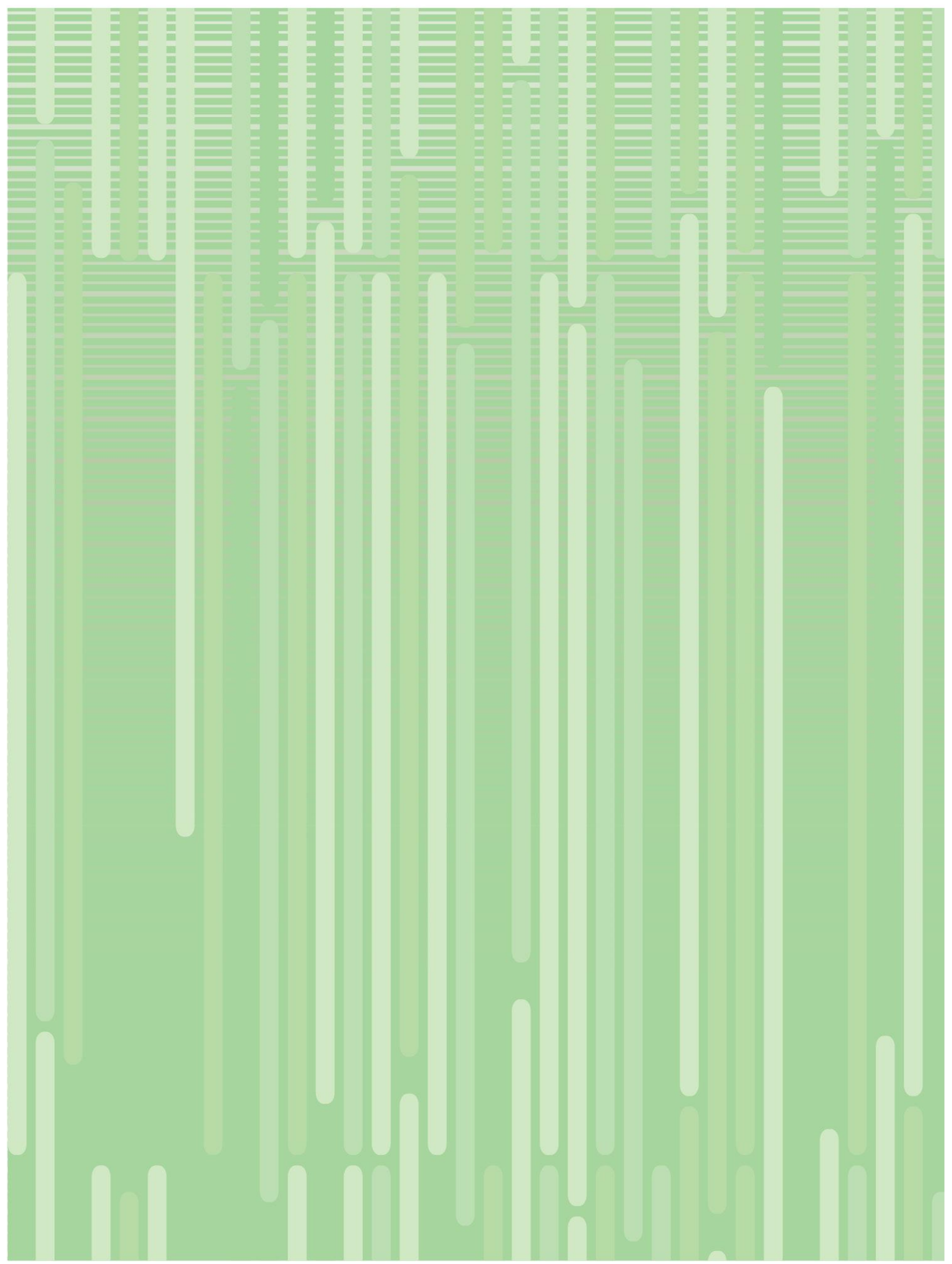

